\title{
Positive association between ATP2B1 rs17249754 and essential hypertension: a case-control study in Burkina Faso, West Africa
}

Herman Karim Sombié ${ }^{1}$, Jonas Koudougou Kologo², Daméhan Tchelougou', Serge Yannick Ouédraogo', Abdoul Karim Ouattara ${ }^{1,3}$, Tegwindé Rebecca Compaoré1, Bolni Marius Nagalo1, Abel Pegdwendé Sorgho', Issoufou Nagabila ${ }^{2}$, Serge Théophile Soubeïga ${ }^{1,3}$, Florencia Wendkuuni Djigma ${ }^{1,3^{*}}$ (D), Albert Théophane Yonli ${ }^{1,3}$, Patrice Zabsonré, ${ }^{5}$ Hassanata Millogo ${ }^{3}$ and Jacques Simporé $e^{1,2,3,4}$

\begin{abstract}
Background: Genetic and environment play a significant role in the etiology of essential hypertension (EH). Recently STK39 rs3754777, ATP2B1 rs2681472 and rs17249754 have been associated with BP variation and hypertension. In this study we aimed to determine firstly whether index variants were associated with the risk of developing EH in Burkina Faso and secondly to characterize cardiovascular risk markers.

Methods: We conducted a case-control study with 380 participants including 180 case subjects with EH and 200 control subjects with normal BP. We used TaqMan genotyping assays with probes from Applied Biosystems to genotype polymorphisms using the 7500 Real-Time PCR System. Biochemical parameters were measured using chemistry analyzer COBAS C311.

Results: T-test showed that cardiovascular risk markers such as body mass index, waist circumference, blood sugar, total cholesterol and triglycerides were significantly higher in hypertensive compared to normotensive (all $p<0.05$ ). Binary logistic regression analysis revealed in decreasing order that overweight, family history of hypertension, central obesity and alcohol intake increased the risk of developing EH (all OR $>3.8$; all $p<0.001$ ).

In genetic level we observed that individuals carrying the AA+AG genotype of ATP2B1 rs17249754 had a low risk of developing $\mathrm{EH}$ than those carrying the $\mathrm{GG}$ genotype $(\mathrm{OR}=0.48[95 \% \mathrm{Cl}: 0.31-0.75] p=0.001)$ and the A allele frequency in the cases was significantly lower than that of the controls ( $\mathrm{OR}=0.56$ [95\% Cl: 0.38-0.82] $p=0.003)$. We also observed that ATP2B1 rs17249754 was significantly associated with higher SBP and DPB in case and control groups (GG versus AG + AA; $p<0.05$ ), ATP2B1 rs2681472 was significantly associated with higher SBP only in case and control group (AA versus AG + GG; $p<0.05$ ), STK39 rs3754777 was not significantly associated with any of the $B P$ traits (CC versus $C T+\Pi$; $p>0.05$ ).
\end{abstract}

Conclusion: Our results confirmed the significant association of ATP2B1 rs17249754 with the risk of developing EH in Burkinabe and showed an increase of cardiovascular risk markers levels in subjects with EH.

Keywords: ATP2B1, STK39, Essential hypertension, Burkina Faso

\footnotetext{
* Correspondence: florencia.djigma@gmail.com; f.djigma@labiogene.org

${ }^{1}$ Department of Microbiology and Biochemistry, Laboratory of Molecular

Biology and Genetics (LABIOGENE), University Ouaga I Prof. Joseph Ki-Zerbo,

P.O. Box 7021, Ouagadougou 03, Burkina Faso

${ }^{3}$ Pietro Annigoni Biomolecular Research Center (CERBA), P.O. Box 364,

Ouagadougou 01, Burkina Faso

Full list of author information is available at the end of the article
}

(c) The Author(s). 2019 Open Access This article is distributed under the terms of the Creative Commons Attribution 4.0 International License (http://creativecommons.org/licenses/by/4.0/), which permits unrestricted use, distribution, and reproduction in any medium, provided you give appropriate credit to the original author(s) and the source, provide a link to the Creative Commons license, and indicate if changes were made. The Creative Commons Public Domain Dedication waiver (http://creativecommons.org/publicdomain/zero/1.0/) applies to the data made available in this article, unless otherwise stated. 


\section{Background}

Cardiovascular diseases are the leading cause of mortality in the world and represent $31 \%$ of global deaths [1]. The common risk factors for developing cardiovascular disorders are obesity, arterial hypertension, diabetes and dyslipidemia [2].

Hypertension is the main leading causes for morbidity and mortality of cardiovascular diseases and affects about one-third of adults worldwide each year [3, 4]. Hypertension was once considered rare in Africa, but currently it has become a public health concern. Several studies estimated at $16.2 \%$ the overall prevalence of hypertension in 74.4 millions of hypertensive individuals in sub-Saharan Africa and the number of affected individuals will increase by $68 \%$ (125.5 million) by 2025 [5]. The causes of EH which accounts for $95 \%$ of cases of hypertension remain largely unknown, however interplay among genetic and non genetic factors might contribute to its etiology [6]. An estimated $30-60 \%$ of blood pressure variation is explained by genetic factors [7]. Determinants also include life-style [8], obesity [9] and environment which can impact blood pressure or risk of hypertension through the influence on gene expression or through interaction with gene products [10].

Recently, with the enormous progress made in molecular Biology domain, Genome-wide association studies (GWAS) have identified news genes and their variants which are associated with blood pressure variations and the risk of hypertension such as STK39 rs3754777 [11], ATP2B1 rs2681472 and rs17249754 [12]. In addition, other reports confirmed these associations in Asian and European population [7, 13-16], but not all.

In this work, we genotyped index variants from these 2 candidate loci identified by studies and examined for the first time the association between them and systolic blood pressure (SBP), diastolic blood pressure (DBP) and the risk of developing EH in Burkina Faso, West Africa and in a second time we characterized some cardiovascular risk markers in patients with $\mathrm{EH}$. The results will be instrumental in the future for a better clinical management of cardiovascular diseases in the country.

\section{Methods}

\section{Study design}

This case-control study was performed in Burkina Faso located in West Africa. A detailed description of our study population has been published previously [17]. Briefly 380 age-sex matched subjects from 20 to 75 years were recruited in the same geographical area of central region in Burkina Faso, including 180 subjects newly diagnosed with $\mathrm{EH}$ as case group and 200 subjects having normal blood pressure as control group.
Patients with EH were diagnosed by the cardiologist in the absence of secondary causes and recruited from the service of cardiology of Saint Camille hospital and the University Hospital Center Yalgado Ouedraogo of Ouagadougou. Hypertension was defined as systolic blood pressure $(\mathrm{SBP}) \geq 140 \mathrm{mmHg}$ and/or diastolic blood pressure $(\mathrm{DBP}) \geq 90 \mathrm{mmHg}$ [18].

Controls were subjects with $\mathrm{SBP}<130 \mathrm{mmHg}$ and $\mathrm{DBP}<80 \mathrm{mmHg}$ without antihypertensive treatments (to avoid pre-hypertension) and without any previous history of high blood pressure. They were recruited in general consultation in the same centers.

Patients who are already taking antihypertensive medications, patients with secondary hypertension or chronic diseases and pregnant women were excluded to avoid confusion.

\section{Samples and data collection}

We recorded using a questionnaire followed by a medical examination, socio-anthropometric parameters (age, sex, waist circumference, weight and height), lifestyle (smoking, alcohol intake), family history of HTA and clinical parameters such as systolic blood pressure (SBP) and diastolic blood pressure (DBP).

Information about the participant's age (years) was based on their self-reported birth year.

Body weight and height were measured respectively by using standardized scale and stadiometer. Body mass index (BMI) was obtained by dividing a person's weight (kilograms) by the square of the person's height (meters). Overweight was defined when BMI $\geq 25 \mathrm{Kg} / \mathrm{m}^{2}$.

Waist circumference (WC) was a measure of the distance around the abdomen in centimeter while the subject was at minimal respiration by using measuring tape. Central obesity was determinate when WC $>102 \mathrm{~cm}$ for men and WC $>88 \mathrm{~cm}$ for women [19].

Smoking status and alcohol intake were dichotomized respectively into smokers versus nonsmokers and drinkers versus nondrinkers.

We defined family history of hypertension like having someone in your family (a blood relative such as a mother, father, sister, or brother) who has or had high blood pressure before the age of 60 years old.

Blood pressure values were measured 3 consecutive times, after $10 \mathrm{~min}$ of seated rest before the first measurement and 5 min intervals between each measurement with a manual aneroid sphygmomanometer. The average of the 3 measurements was used for analyses.

We also collected $8 \mathrm{ml}$ of fasting venous blood in tube containing anticoagulant (EDTA) and tube without anticoagulant for analyses. Serum was used to determine High density lipoprotein cholesterol (HDL-c), low density lipoprotein cholesterol (LDL-c), total cholesterol 
(TC), triglycerides and blood sugar using the COBAS C311 chemistry analyzer (Roche-Hitachi, France).

\section{DNA extraction and genotyping of polymorphisms}

Genomic DNA was isolated from peripheral blood white cells using the standard salt fractionation method as described by Miller and al. in 1988 [20]. The purity and concentration of DNA were assessed using a Biodrop $\mu$ LITE (Isogen Life Science, N.V/S.A, Temse, Belgium).

Polymorphisms were genotyped by TaqMan allelic discrimination assays with probes labeled with the fluorophores FAM/VIC (C_16057071_10, C_34612217_10 and C_27474774_10) purchased from Applied Biosystems (ABI, Applera International Inc., Foster City, CA, USA). PCRs were performed according to the protocol established by the manufacturer in $25 \mu \mathrm{L}$ reaction volume including $5 \mu \mathrm{L}$ of DNA, $12.5 \mu \mathrm{L}$ of TaqMan Universal PCR Master Mix, $6.25 \mu \mathrm{L}$ of sterilized water and $1.25 \mu \mathrm{L}$ of SNP mix (40X) using 7500 Fast real time PCR system. Fluorescence was analyzed with the 7500 FAST Sequence Detection Software version v.2.1 (Applied Biosystem).

\section{Statistical analysis}

Statistical Package for Social Sciences (SPSS Version 20.0) and Epi Info (Version 6.0) were used for data analysis.

Sample size and power calculations were conducted (Epi Info Version 6.0) by using following values: Twosided confidence level of $95 \%$, power of $80 \%$, ratio of controls to cases 1.1, the proportion exposed in the control group with $50 \%$, odds ratio of 1.8 or greater.

Quantitative variables were expressed as mean \pm standard deviation and comparison between groups was assessed with Student's t-test. Pearson correlation test was used to established correlation.

Investigation of factors increasing the risk of developing EH were done with binary logistic regression analysis (forward stepwise method) by taking hypertensive status as a dependent variable and including some conventional cardiovascular risk markers such as gender (male/ female), overweight (yes/no), central obesity (yes/no), alcohol consumption (yes/no), Smoking (yes/no) and family history of HTA (yes/no).

Associations between polymorphisms and $\mathrm{EH}$ and/ or blood pressure were established by comparing genotypic and allelic frequencies between cases and controls using the chi-squared test and averages of arterial blood pressures between genotypes using Student's t-test respectively.

For all analyses, difference was statistically significant when $p<0.05$.

\section{Results}

\section{Quantitative characteristics}

The characteristics of the study population are given in Table 1. We included 180 subjects with EH as cases and 200 subjects with normal blood pressure as controls. Hypertensive patients were mostly female $(58.68 \%)$. Ttest demonstrated that means of $\mathrm{BMI} \quad(\mathrm{MD}=4.89$; $p<0.001)$, WC $(\mathrm{MD}=10.69 ; p<0.001)$, serum level of blood sugar $(\mathrm{MD}=2.25 ; p<0.001)$, total cholesterol $(\mathrm{MD}=0.78 ; p=0.001)$ and triglycerides $(\mathrm{MD}=0.22 ; p=$ $0.03)$ were significantly higher in cases compared to controls.

We determined Pearson index and we showed positive correlation of age, BMI, WC, blood sugar with systolic and diastolic blood pressure in the study population (case + controls). Only BMI was positively correlated

Table 1 General Characteristics of the study population

\begin{tabular}{|c|c|c|c|c|c|c|}
\hline Parameters & $\begin{array}{c}\text { Total } \\
n=380\end{array}$ & $\begin{array}{c}\text { Cases } \\
n=180\end{array}$ & $\begin{array}{c}\text { controls } \\
n=200\end{array}$ & MD & $\mathrm{Cl}(95 \%)$ & $p$ values \\
\hline $\operatorname{Sex}(M / F)$ & $157 / 223$ & $74 / 106$ & $83 / 117$ & - & - & 1 \\
\hline Age (years) & $48.98 \pm 11.32$ & $48.21 \pm 10.09$ & $49.67 \pm 12.31$ & -1.45 & $-3.74-0.82$ & 0.21 \\
\hline $\mathrm{SBP}(\mathrm{mmHg})$ & $140.50 \pm 30.36$ & $167.58 \pm 20.0$ & $116.13 \pm 11.6$ & 51.45 & $48.18-54.71$ & $<0.001 *$ \\
\hline DBP $(\mathrm{mmHg})$ & $84.95 \pm 16.81$ & $98.73 \pm 12.15$ & $72.55 \pm 8.90$ & 26.18 & $24.05-28.32$ & $<0.001 *$ \\
\hline $\mathrm{BMI}\left(\mathrm{kg} / \mathrm{m}^{2}\right)$ & $25.90 \pm 6.45$ & $28.48 \pm 7.18$ & $23.58 \pm 4.63$ & 4.89 & $3.68-6.10$ & $<0.001 *$ \\
\hline WC (cm) & $88.87 \pm 12.60$ & $94.50 \pm 13.33$ & $83.81 \pm 9.39$ & 10.69 & $8.38-13.00$ & $<0.001 *$ \\
\hline Blood sugar (mmol/l) & $5.10 \pm 1.57$ & $5.94 \pm 2.84$ & $3.69 \pm 1.66$ & 2.25 & $1.36-3.14$ & $<0.001 *$ \\
\hline HDL-c (mmol/l) & $1.27 \pm 0.52$ & $1.38 \pm 0.55$ & $1.08 \pm 0.42$ & 0.29 & $0.04-0.46$ & $0.002 *$ \\
\hline LDL-c (mmol/l) & $3.03 \pm 1.14$ & $3.17 \pm 1.10$ & $2.60 \pm 1.15$ & 0.57 & $0.17-0.96$ & $0.005 *$ \\
\hline $\mathrm{TC}(\mathrm{mmol} / \mathrm{l})$ & $5.00 \pm 1.36$ & $5.13 \pm 1.21$ & $4.34 \pm 1.48$ & 0.78 & $0.32-1.24$ & $0.001 *$ \\
\hline Triglyceride (mmol/l) & $1.24 \pm 0.68$ & $1.23 \pm 0.56$ & $1.00 \pm 0.65$ & 0.22 & $0.01-0.43$ & $0.03 *$ \\
\hline
\end{tabular}

Values are Median \pm SD for continuous variables; Cases versus controls (t-test); $*$ Significant $p$ value; HDL-c high density lipoprotein cholesterol, $L D L-c$ low density lipoprotein cholesterol, $T C$ total cholesterol, $M$ male, $F$ female, $B M I$ body mass index, WC waist circumference, DBP diastolic blood pressure, SBP systolic blood pressure, $M D$ means difference 
with all other variables studied such as serum level of blood sugar, TC, HDL-c, LDL-c and Triglycerides (data not shown). Additional file 1: Table S1.

Binary logistic regression analysis revealed that in decreasing order, overweight, family history of HTA, central obesity and alcohol intake increased the risk of developing EH (all OR $>3.87$; all $p<0.001$ ) Table 2.

\section{Genetics analysis}

Genotypic frequencies of the study polymorphisms are given in Table 3. A total of 380 subjects were genotyped for ATP2B1 gene polymorphisms (rs2681472, rs17249754) and STK39 gene polymorphism (rs3754777). All three polymorphisms genotypes didn't deviate from the HardyWeinberg equilibrium $(p>0.05)$. In the general population, we found that genotypic frequencies of rs 2681472 were $2.1 \%$ for GG, $16.1 \%$ for GA and $81.8 \%$ for AA; genotypic frequencies of rs 17249754 were $2.6 \%$ for $\mathrm{AA}, 30.0 \%$ for AG, $67.4 \%$ for GG; genotypic frequencies of rs3754777 were $2.1 \%$ for TT, $25.3 \%$ for TC, $72.6 \%$ for CC.

When we compared genotypic and allelic frequencies between cases and controls and average of SBP and DBP between genotypes, we observed that individuals carrying the AA+AG genotype of ATP2B1 rs17249754 had a low risk of developing $\mathrm{EH}$ than those carrying the GG genotype $(\mathrm{OR}=0.48$ [95\% CI: $0.31-0.75] p=0.001)$. In addition, the A allele frequency of ATP2B1 rs17249754 in the case group was significantly lower than that of the control group (allelic OR $=0.56$ [95\% CI: 0.38-0.82] allelic $p=0.003)$. We didn't find any significant associations of ATP2B1 rs2681472 and STK39 rs3754777 with the risk of developing $\mathrm{EH}$ in our study population (all $p>0.05)$ Table 4.

We also observed that ATP2B1 rs17249754 was significantly associated with higher SBP and DPB (GG versus AG + AA; $p<0.05)$ in cases and controls groups; $A T P 2 B 1$ rs2681472 was significantly associated with higher SBP only in case and control group (AA versus AG + GG; $p<0.05)$; STK39 rs3754777 was not associated with any of the BP traits (CC versus CT + TT; $p>$ 0.05). data not shown. Additional file 2: Table S2.

Table 2 Factors increasing risk of essential hypertension

\begin{tabular}{lccc}
\hline Factors & OR & $95 \% \mathrm{Cl}$ & $p$ values \\
\hline Gender M/F & 0.91 & $0.54-1.53$ & 1 \\
Overweight & 5.24 & $2.92-9.43$ & $<0.0001 *$ \\
Central obesity & 4.57 & $3.37-6.20$ & $<0.0001 *$ \\
Alcohol intake & 3.87 & $2.47-6.08$ & $<0.0001 *$ \\
Smoking & 1.37 & $0.66-2.8$ & 0.46 \\
Family history of HTA & 5.19 & $3.32-8.13$ & $<0.0001 *$ \\
\hline WC waist circumference, BMI body mass index, $M$ male, $F$ female, ${ }^{*}$ significant \\
$p$ value
\end{tabular}

\section{Discussion}

Hypertensive patients often present metabolic disorders which impact their quality of life and could increase their risk of developing cardiovascular diseases. In our study we characterized known cardiovascular risk markers in subjects with EH (cases) and normotensive individuals (controls). The results showed that subjects with $\mathrm{EH}$ had significantly higher levels of blood sugar $(p<0.001)$, BMI $(p<0.001)$ and total cholesterol $(p<0.05)$ compared to controls. These findings suggest that subjects with EH tend to develop disorders associated with metabolic syndrome as described previously [21]. These markers were positively correlated to the augmentation of systolic and diastolic blood pressure in our study population, supporting those several independent studies conducted in different population which showed that risk of hypertension increased with age [22] and BMI [23], and that dyslipidemia [24] and hyperglycemia [25] were more frequent in hypertensive compared to normotensive individuals. Epidemiological studies have demonstrated that Obesity and overweight were associated with an increase of cardiovascular risk markers [26], in our study we also found that BMI was positively correlated to all other cardiovascular risk markers such us SBP, DBP, HDL-c, LDL-c, TC, triglycerides and blood sugar level. Regular physical activities have been shown to reduce the risk of high blood pressure and could also help lipids repartition in the organism [27], in our study we also found that obese and overweight patients who are usually less active were the main group at risk of developing cardiovascular disorders as previously described [28].

In the genetic level we investigated the effect of genetic loci recently identified by GWAS with BP and the risk of developing EH. Our first gene of interest ATP2B1 also named PMCA1 (Plasma Membrane Calcium ATPase type 1) is located in chromosome 12, position 12q21.q23 and belongs to the P-type pump family [29]. It encoded a protein responsible for the regulated transport between the intracellular and the extracellular milieu of $\mathrm{Ca}^{2+}$, an ion which contributes to contractionrelaxation of vascular smooth muscles [30]. Mechanism by which $A T P 2 B 1$ gene influences blood pressure is not yet clear but, investigations showed its mRNA overexpression in hypertensive animal models compared to normotensive [31] and an excessive increase of blood pressure through vasoconstriction in $A T P 2 B 1$ gene deleted rats [32]. These findings may explain among other things the mechanism by which changes in the ATP2B1 gene product levels are involved in $\mathrm{BP}$ regulation and risk of $\mathrm{EH}$. In our study we observed that individuals carrying the AA+AG genotype of ATP2B1 rs17249754 had a low risk of developing $\mathrm{EH}$ than those carrying the GG genotype $(\mathrm{OR}=0.48 ; 95 \% \mathrm{CI}=0.31-0.75 ; p=0.001)$. 
Table 3 Distribution of the genotypes frequency in the study population

\begin{tabular}{|c|c|c|c|c|}
\hline SNPS & Genotypes & $\begin{array}{c}\text { Cases + Controls } \\
n=380(100 \%)\end{array}$ & $\begin{array}{c}\text { Cases } \\
n=180(100 \%)\end{array}$ & $\begin{array}{c}\text { Controls } \\
n=200(100 \%)\end{array}$ \\
\hline \multirow[t]{3}{*}{ rs2681472 } & GG & $8(2.1)$ & $4(2.2)$ & $4(2.0)$ \\
\hline & GA & $61(16.1)$ & 27 (15.0) & $34(17.0)$ \\
\hline & AA & 311 (81.8) & 149 (82.8) & $162(81.0)$ \\
\hline HWE $p$ value & & 0.09 & 0.24 & 0.30 \\
\hline \multirow[t]{3}{*}{ rs17249754 } & AA & $10(2.6)$ & $4(2.2)$ & $6(3.0)$ \\
\hline & $A G$ & $114(30.0)$ & $40(22.2)$ & $74(37.0)$ \\
\hline & GG & $256(67.4)$ & $136(75.6)$ & $120(60.0)$ \\
\hline HWE $p$ value & & 0.78 & 0.80 & 0.45 \\
\hline \multirow[t]{3}{*}{ rs3754777 } & $\Pi$ & $8(2.1)$ & $4(2.2)$ & $4(2.0)$ \\
\hline & $\mathrm{TC}$ & $96(25.3)$ & $46(25.6)$ & $50(25.0)$ \\
\hline & $\mathrm{CC}$ & $276(72.6)$ & $130(72.2)$ & $146(73.0)$ \\
\hline HWE $p$ value & & 0.85 & 1.00 & 1.00 \\
\hline
\end{tabular}

HWE Hardy-Weinberg equilibrium

Furthermore, the A allele frequency of $A T P 2 B 1$ rs17249754 in the case group was significantly lower than that of the control group (allelic OR $=0.56$; $95 \%$ $\mathrm{CI}=0.38-0.82$; allelic $p=0.003$ ). The association of $A T P 2 B 1$ rs17249754 with hypertension has been previously shown in Koreans [12]. Subsequently GWA studies conducted by the Global Blood Pressure Genetics and CHARGE consortiums confirmed this association [13]. Recently Daily and al. in Korean, showed that carriers of the major allele $\mathrm{G}$ of $A T P 2 B 1$ rs17249754 were at greater risk of developing hypertension and that high $\mathrm{Na}$ intake and low $\mathrm{Ca}$ increased the risk more in major allele than among minor allele carrier, suggesting that people with the $\mathrm{G}$ allele can reduce risk of high blood pressure by having good calcium status [33]. Interaction of BMI, gender and $A T P 2 B 1$ rs17249754 in susceptibility to hypertension has been also reported in Han Chinese Population [15]. In our study, we were unable to perform sub-group analysis given the limited number of participants. Concerning ATP2B1 rs2681472, it was found to be associated with hypertension firstly in 2009 by Levy and al. [7]. In our cohort, we didn't find any significant association between it and essential hypertension, but we found that individuals carrying the AA genotype had high SBP than those carrying the GG + AG genotype. The association between rs17249754 and EHT demonstrate the potential role of $A T P 2 B 1$ in the regulation of blood pressure and treatment of EHT. Indeed, Okuyama and al., showed that mice lacking $A T P 2 B 1$ had a higher response to CCBs for blood pressure-lowering effects than other anti-hypertensive drugs [34], and previously Tabara and al. showed that it

Table 4 Associations between polymorphisms and risk of essential hypertension

\begin{tabular}{|c|c|c|c|c|c|c|}
\hline SNPS & & $\begin{array}{l}\text { Cases, } n(\%) \\
180(100 \%)\end{array}$ & $\begin{array}{c}\text { Controls, n (\%) } \\
200(100 \%)\end{array}$ & OR & $\mathrm{Cl}(95 \%)$ & $p$ values \\
\hline \multirow[t]{4}{*}{ rs2681472 } & GG versus $A G+A A, n(\%)$ & $4(2.2)$ & $4(2.0)$ & 1.11 & $0.27-4.51$ & 1.00 \\
\hline & $\mathrm{GG}+\mathrm{AG}$ versus $\mathrm{AA}, n(\%)$ & $31(17.2)$ & $38(19.0)$ & 0.88 & $0.52-1.49$ & 0.69 \\
\hline & A (\%) & 90.3 & 89.5 & - & - & - \\
\hline & G (\%) & 9.7 & 10.5 & 0.91 & $0.57-1.47$ & 0.80 \\
\hline \multirow[t]{4}{*}{ rs17249754 } & $A A$ versus $A G+G G, n(\%)$ & $4(2.2)$ & $6(3.0)$ & 0.73 & $0.20-2.64$ & 0.75 \\
\hline & $\mathrm{AA}+\mathrm{AG}$ versus $\mathrm{GG}, n(\%)$ & $44(24.4)$ & $80(40.0)$ & 0.48 & $0.31-0.75$ & $0.001 *$ \\
\hline & G (\%) & 86.7 & 78.5 & - & - & - \\
\hline & A (\%) & 13.3 & 21.5 & 0.56 & $0.38-0.82$ & $0.003 *$ \\
\hline \multirow[t]{4}{*}{ rs3754777 } & TT versus TC + CC, $n(\%)$ & $4(2.0)$ & $4(2.0)$ & 1.11 & $0.27-4.51$ & 1.00 \\
\hline & $\pi+\mathrm{TC}$ versus CC, $n(\%)$ & $50(28.0)$ & $54(27.0)$ & 1.03 & $0.66-1.63$ & 0.90 \\
\hline & C (\%) & 85.0 & 85.5 & - & - & - \\
\hline & Т (\%) & 15.0 & 14.5 & 1.04 & $0.69-1.55$ & 0.90 \\
\hline
\end{tabular}

*, significant $p$ value; NA not available 
may be a reduction in the expression of $A T P 2 B 1$ which leads to raised blood pressure in those with a $A T P 2 B 1$ risk allele for hypertension [35]. These data may suggest that hypertensive patients with variant $\mathrm{G}$ of rs17249754 (risk allele for hypertension) may also have a reduction in the expression of $A T P 2 B 1$ and therefore a better response to $\mathrm{CCBs}$ compared to other antihypertensive drugs. However, further studies are needed to confirm that.

Our second gene of interest STK39, encodes a serinethreonine kinase named STE20/SPS1-related proline/alanine-rich kinase (SPAK), which seems to impact blood pressure by its action on renal excretion of sodium through its interaction with the WNK kinase and cotransporters cation-chloride [36]. Experimental studies showed that rats in which SPAK and WNK interaction were blocked had a lower blood pressure [37]. In the present study, we didn't find any significant association of STK39 rs3754777 with EH as reported previously in Amish, non Amish [11], Belgian population [16] and male Han Chinese [38]. However, certain studies before ours reached to the same conclusion and failed to prove any association such as studies in British Caucasian [39] and Chinese Children [40].

In view of our results and other results obtained in previous studies, we can note a strong interaction between genetic variants and environmental and/or epigenetic factors, so that certain genetic variants only have significant effect in specific populations.

\section{Conclusion}

In conclusion, our study confirmed the significant association between ATP2B1 rs17249754 and EH in Burkinabe, suggesting the potential role of $A T P 2 B 1$ in the regulation of blood pressure. It also showed a significant increase of cardiovascular risk markers in individuals with $\mathrm{EH}$ compared to normotensive and once again invite clinicians to be looking at the level of BMI, WC and cholesterol in the management of EH. However, the present research has some limitations, particularly the small size of the study population. A large scale study will be necessary to fully comprehend the role of $A T P 2 B 1$ rs17249754 in the development of $\mathrm{EH}$ and response to CCBs in Burkina Faso.

\section{Additional files}

Additional file 1: Table S1. Correlation between blood pressure and cardiovascular risk markers. This file shows correlation between known cardiovascular risk markers such as SBP, DBP, age, BMI, WC, serum level of blood sugar, TC, HDL-C, LDL-C and Triglycerides in the general study population. (DOCX $13 \mathrm{~kb}$ )

Additional file 2: Table S2. Distribution of systolic and diastolic blood pressure according to genotypes. This file presents the results of association analysis between genetic polymorphisms studied and SBP or DBP in cases and controls. (DOCX $13 \mathrm{~kb}$ )

\section{Abbreviations}

ATP2B1: ATPase plasma membrane $\mathrm{Ca}^{2+}$ transporting 1; BMI: Body mass index; CERBA: Pietro Annigoni biomolecular research center; DBP: Diastolic blood pressure; EDTA: Ethylenediaminetetraacetic; EH: Essential hypertension; GWAS: Genome-wide association study; HDL-c: High-density lipoprotein cholesterol; LABIOGENE: Laboratory of molecular biology and genetics; LDLc: Low-density lipoprotein cholesterol; MD: Means difference;

PCR: Polymerase chain reaction; SBP: Systolic blood pressure; SD: Standard deviation; SPAK: STE20/SPS1-related proline/alanine-rich kinase;

SPSS: Statistical package for the social sciences; STK39: Serine/threonine kinase 39; TC: Total cholesterol; WC: Waist circumference; WNK: With-no-K (Lys)

\section{Acknowledgements}

The authors wish to thank all participants in this study. A deep gratitude to all the staff of Saint Camille Hospital of Ouagadougou (HOSCO) and Biomolecular Research Center Pietro Annigoni (CERBA) for technical support.

\section{Authors' contributions}

Study concept and design: HM, JKK and JS. Sampling and Laboratory analysis: HKS, DT, SYO, APS, AKO, IN and JKK. Statistical analysis and interpretation of data: HKS, APS, STS, ATY and DT. Drafting of the manuscript: FWD, HKS, APS, BMN, SYO, AKO, RTC and JS. Critical revision of the manuscript for important intellectual content: FWD, BMN, HM, JKK, PZ and JS. Administrative, technical, and material support: FWD, ATY, JKK and JS. Study supervision: JKK, HM, PZ and JS. All authors read and approved the final manuscript.

\section{Funding}

This work was supported by west African economic and monetary union (WAEMU) through the "Programme d'appui et de développement des centres d'excellence régionaux" (PACER II) and "Centre national de l'Information, de I'Orientation Scolaire et Professionnelle, et des Bourses" (CIOSPB) especially for researcher life stipend. Financial support for reagents and consumables was provided by Italian episcopal conference (CEI)

\section{Availability of data and materials}

The datasets used and/or analyzed during the current study are available from the corresponding author on reasonable request.

\section{Ethics approval and consent to participate}

The present study has been approved by the ethics committee of CERBA/ LABIOGENE. Free and written consent was obtained from all participants of this study. The anonymity and confidentiality of the patients were respected as stated in the IRB (Institutional Review Board) protocol.

\section{Consent for publication}

Not Applicable.

\section{Competing interests}

The authors declare that they have no competing interests.

\section{Author details}

${ }^{1}$ Department of Microbiology and Biochemistry, Laboratory of Molecular Biology and Genetics (LABIOGENE), University Ouaga I Prof. Joseph Ki-Zerbo, P.O. Box 7021, Ouagadougou 03, Burkina Faso. ${ }^{2}$ Saint Camille hospital in Ouagadougou (HOSCO), Burkina Faso, P.O. Box 444, Ouagadougou 01, Burkina Faso. ${ }^{3}$ Pietro Annigoni Biomolecular Research Center (CERBA), P.O. Box 364, Ouagadougou 01, Burkina Faso. ${ }^{4}$ Faculty of Medicine, University Saint Thomas d'Aquin, P.O. Box 10212, Ouagadougou, Burkina Faso. ${ }^{5}$ University Hospital Center-Yalgado Ouedraogo (CHUYO), Ouagadougou, Burkina Faso.

Received: 6 February 2019 Accepted: 12 June 2019

Published online: 26 June 2019

References

1. Kearney PM, Whelton M, Reynolds K, Muntner P, Whelton PK, He J. Global burden of hypertension: analysis of worldwide data. Lancet. 2005;365(9455): 217-23 
2. Thomas AG, Michael JG. Harrison's principles of internal medicine. Philadelphia: Elsevier Saunders; 2012.

3. Lewington S, Clarke R, Qizilbash N, Peto R, Collins R, Prospective Studies C. Age-specific relevance of usual blood pressure to vascular mortality: a metaanalysis of individual data for one million adults in 61 prospective studies. Lancet. 2002;360(9349):1903-13.

4. Lawes CM, Vander Hoorn S, Rodgers A. International Society of H: global burden of blood-pressure-related disease, 2001. Lancet. 2008;371(9623): 1513-8

5. Ogah OS, Rayner BL. Recent advances in hypertension in sub-Saharan Africa. Heart. 2013;99(19):1390-7.

6. Binder A. A review of the genetics of essential hypertension. Curr Opin Cardiol. 2007;22(3):176-84.

7. Levy D, Ehret GB, Rice K, Verwoert GC, Launer L, Dehghan A, Glazer NL, Morrison AC, Johnson AD, Aspelund T, et al. Genome-wide association study of blood pressure and hypertension. Nat Genet. 2009;41(6):677-87.

8. Blair SN, Goodyear NN, Gibbons LW, Cooper KH. Physical fitness and incidence of hypertension in healthy normotensive men and women. Jama. 1984;252(4):487-90.

9. Field AE, Coakley EH, Must A, Spadano JL, Laird N, Dietz WH, Rimm E, Colditz GA. Impact of overweight on the risk of developing common chronic diseases during a 10-year period. Arch Intern Med. 2001;161(13): 1581-6.

10. Pausova Z, Tremblay J, Hamet P. Gene-environment interactions in hypertension. Curr Hypertens Rep. 1999;1(1):42-50.

11. Wang Y, O'Connell JR, McArdle PF, Wade JB, Dorff SE, Shah SJ, Shi X, Pan L, Rampersaud E, Shen $\mathrm{H}$, et al. From the cover: whole-genome association study identifies STK39 as a hypertension susceptibility gene. Proc Natl Acad Sci U S A. 2009;106(1):226-31.

12. Cho YS, Go MJ, Kim YJ, Heo JY, Oh JH, Ban HJ, Yoon D, Lee MH, Kim DJ, Park $M$, et al. A large-scale genome-wide association study of Asian populations uncovers genetic factors influencing eight quantitative traits. Nat Genet. 2009;41(5):527-34.

13. Hong KW, Go MJ, Jin HS, Lim JE, Lee JY, Han BG, Hwang SY, Lee SH, Park HK, Cho YS, et al. Genetic variations in ATP2B1, CSK, ARSG and CSMD1 loci are related to blood pressure and/or hypertension in two Korean cohorts. J Hum Hypertens. 2010;24(6):367-72.

14. Xi B, Chen M, Chandak GR, Shen Y, Yan L, He J, Mou SH. STK39 polymorphism is associated with essential hypertension: a systematic review and meta-analysis. PLoS One. 2013;8(3):e59584.

15. Xu J, Qian HX, Hu SP, Liu LY, Zhou M, Feng M, Su J, Ji LD. Gender-specific association of ATP2B1 variants with susceptibility to essential hypertension in the Han Chinese population. Biomed Res Int. 2016:1910565.

16. Persu A, Evenepoel L, Jin Y, Mendola A, Ngueta G, Yang WY, Gruson D, Horman S, Staessen JA, Vikkula M. STK39 and WNK1 are potential hypertension susceptibility genes in the BELHYPGEN cohort. Medicine (Baltimore). 2016;95(15):e2968.

17. Tchelougou D, Kologo JK, Karou SD, Yameogo VN, Bisseye C, Djigma FW, Ouermi D, Compaore TR, Assih M, Pietra V, et al. Renin-angiotensin system genes polymorphisms and essential hypertension in Burkina Faso, West Africa. Int J Hypertens. 2015;2015:979631.

18. Chalmers J, MacMahon S, Mancia G, Whitworth J, Beilin L, Hansson L, Neal B, Rodgers A, Ni Mhurchu C, Clark T: 1999 World Health OrganizationInternational Society of Hypertension Guidelines for the management of hypertension. Guidelines sub-committee of the World Health Organization. Clin Exp Hypertens 1999, 21(5-6):1009-1060.

19. Zhang C, Rexrode KM, van Dam RM, Li TY, Hu FB. Abdominal obesity and the risk of all-cause, cardiovascular, and cancer mortality: sixteen years of follow-up in US women. Circulation. 2008;117(13):1658-67.

20. Miller SA, Dykes DD, Polesky HF. A simple salting out procedure for extracting DNA from human nucleated cells. Nucleic Acids Res. 1988;16(3): 1215.

21. Alberti KG, Zimmet PZ. Definition, diagnosis and classification of diabetes mellitus and its complications. Part 1: diagnosis and classification of diabetes mellitus provisional report of a WHO consultation. Diabetic medicine : a journal of the British Diabetic Association. 1998:15(7):539-53.

22. Vasan RS, Beiser A, Seshadri S, Larson MG, Kannel WB, D'Agostino RB, Levy D. Residual lifetime risk for developing hypertension in middle-aged women and men: the Framingham heart study. Jama. 2002;287(8):1003-10

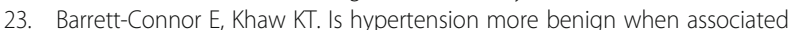
with obesity? Circulation. 1985;72(1):53-60.
24. Laaksonen DE, Niskanen L, Nyyssonen K, Lakka TA, Laukkanen JA, Salonen JT. Dyslipidaemia as a predictor of hypertension in middle-aged men. Eur Heart J. 2008;29(20):2561-8

25. Takatori S, Zamami Y, Hashikawa-Hobara N, Kawasaki H. Insulin resistanceinduced hypertension and a role of perivascular CGRPergic nerves. Curr Protein Pept Sci. 2013;14(4):275-81.

26. Loprinzi PD, Crespo CJ, Andersen RE, Smit E. Association of body mass index with cardiovascular disease biomarkers. Am J Prev Med. 2015;48(3): 338-44.

27. Borhani NO. Significance of physical activity for prevention and control of hypertension. J Hum Hypertens. 1996;10(Suppl 2):S7-11.

28. Hu G, Pekkarinen H, Hanninen O, Yu Z, Guo Z, Tian H. Commuting, leisuretime physical activity, and cardiovascular risk factors in China. Med Sci Sports Exerc. 2002;34(2):234-8.

29. Olson S, Wang MG, Carafoli E, Strehler EE, McBride OW. Localization of two genes encoding plasma membrane Ca2(+)-transporting ATPases to human chromosomes 1q25-32 and 12q21-23. Genomics. 1991;9(4):629-41.

30. Holloway ET, Bohr DF. Reactivity of vascular smooth muscle in hypertensive rats. Circ Res. 1973:33(6):678-85.

31. Monteith GR, Kable EP, Kuo TH, Roufogalis BD. Elevated plasma membrane and sarcoplasmic reticulum Ca2+ pump mRNA levels in cultured aortic smooth muscle cells from spontaneously hypertensive rats. Biochem Biophys Res Commun. 1997;230(2):344-6.

32. Shin YB, Lim JE, Ji SM, Lee HJ, Park SY, Hong KW, Lim M, McCarthy MI, Lee $\mathrm{YH}, \mathrm{Oh} \mathrm{B}$. Silencing of Atp2b1 increases blood pressure through vasoconstriction. J Hypertens. 2013;31(8):1575-83.

33. Daily JW, Kim BC, Liu M, Park S. People with the major alleles of ATP2B1 rs17249754 increases the risk of hypertension in high ratio of sodium and potassium, and low calcium intakes. J Hum Hypertens. 2017;31(12):787-94.

34. Okuyama Y, Hirawa N, Fujita M, Fujiwara A, Ehara Y, Yatsu K, Sumida K, Kagimoto M, Katsumata M, Kobayashi Y, et al. The effects of antihypertensive drugs and the mechanism of hypertension in vascular smooth muscle cell-specific ATP2B1 knockout mice. Hypertens Res. 2017;41:80.

35. Tabara Y, Kohara K, Kita Y, Hirawa N, Katsuya T, Ohkubo T, Hiura Y, Tajima A, Morisaki T, Miyata T, et al. Common variants in the ATP2B1 gene are associated with susceptibility to hypertension: the Japanese millennium genome project. Hypertension. 2010;56(5):973-80.

36. Delpire E, Gagnon KB. SPAK and OSR1: STE20 kinases involved in the regulation of ion homoeostasis and volume control in mammalian cells. The Biochemical journal. 2008;409(2):321-31.

37. Rafiqi FH, Zuber AM, Glover M, Richardson C, Fleming S, Jovanovic S, Jovanovic A, O'Shaughnessy KM, Alessi DR. Role of the WNK-activated SPAK kinase in regulating blood pressure. EMBO molecular medicine. 2010;2(2): 63-75.

38. Chen LY, Zhao WH, Tian W, Guo J, Jiang F, Jin LJ, Sun YX, Chen KM, An LL, Li GD, et al. STK39 is an independent risk factor for male hypertension in Han Chinese. Int J Cardiol. 2012;154(2):122-7.

39. Cunnington MS, Kay C, Avery PJ, Mayosi BM, Koref MS, Keavney B. STK39 polymorphisms and blood pressure: an association study in British Caucasians and assessment of cis-acting influences on gene expression. BMC medical genetics. 2009;10:135

40. Xi B, Zhao X, Chandak GR, Shen Y, Cheng H, Hou D, Wang X, Mi J. Influence of obesity on association between genetic variants identified by genomewide association studies and hypertension risk in Chinese children. Am J Hypertens. 2013;26(8):990-6.

\section{Publisher's Note}

Springer Nature remains neutral with regard to jurisdictional claims in published maps and institutional affiliations. 